một số yễu tố liên quan ở trẻ em dưới 5 tuổi tại xã Quyết Tiến, Tiên Lãng, Hải Phòng năm 2019 2020. Tạp chí Y học Dự phòng. 31(5).
7. Victora, C.G., de Onis, M., Hallal, P.C., et al.,(2010). Global database on child growth and malnutrition. Pediatrics. 125: p. e473-e480.

\title{
VAI TRÒ CỦA FIBRINMONOMER HÒA TAN TRONG CHẨN ĐOÁN ĐÔNG MÁU Nô̂I QUẢN RẢI RÁC Ở BÊNH NHÂN SỐC NHIỄM KHUẨN TẠI TRUNG TÂM CẤP CỨU A9 BÊ̂NH VIÊ̂N BẠCH MAI
}

\section{TÓM TẮT}

Mục tiêu: Mô tả sơ bộ tình trạng đông máu nội quản rải rác trên bệnh nhẩn sốc nhiễm khuẩn. Đánh giá vai trò của fibrinmonomer hòa tan trong chẩn đoán đông máu nội quản rải rác trên bệnh nhân sốc nhiếm khuẩn thu thâp được tai trung tâm cấp cứu A9 bệnh viên Bach Mai trong thời gian từ tháng 6 năm 2020 đển tháng 4 năm 2021. Đối tượng và phương pháp nghiên cứu: 61 bệnh nhân được lấy theo phương pháp chọn mẫu thuận tiện,đáp ứng tiêu chuẩn lựa chọn và không có tiêu chuẩn loại trừ, nghiên cứu sử dung thang điểm chẩn đoán đông máu nội quản rải rác(DIC) của ISTH 2001, tiêu chuẩn chẩn đoán sốc nhiễm khuẩn theo Sepsis-3. Kết quả: 61 bệnh nhân sốc nhiễm khuẩn được lấy vào nghiên cứu có đô tuổi trung bình $59.95 \pm 12.23$, nam giới chiếm $73.8 \%$. Nguyên nhân hàng đầu là từ hô hấp đến ổ bung, tiết niêu. Có 34 bênh nhân được chẩn đoán DIC toàn thể chiểm $55.8 \%$. Fibrinmonomer có vai trò trong chẩn đoán DIC với diện tích dưới đường cong ROC, độ đặc hiệu, giá trị dự báo âm tính, giá trị dự báo dương tính cao hơn D-Dimer.

Tư khóa: sốc nhiếm khuẩn, đông máu nội quản rải rác, DIC, fibrin monomer hòa tan, D-dimer, bệnh viện Bạch Mai.

\section{SUMMARY \\ VALUE OF SOLUBE FIBRINMONOMER IN DIAGNOSIS THE DISSEMINATE INTRAVASCULAR COAGULATION IN SEPTIC SHOCK PATIENTS IN CENTER OF EMERGENCY MEDICINE A9, BACHMAI HOSPITAL}

Purpose: Describe characteristics of disseminated intravascular coagulation in patients with septic shock. Evaluation of the role of soluble fibrinmonomer in the diagnosis of disseminated intravascular coagulation in septic shock patients admitted in center of emergency medicine A9, Bach Mai hospital from June 2020 to April 2021. Subjects and methods: 61 patients included. Our study use ISTH 2001 criteria for disseminated intravascular coagulation and Sepsis-3 criteria for septic shock. Results: Mean age is $59.95 \pm$

${ }^{1}$ Trường Đại hoc Y Hà Nọi

${ }^{2}$ Trung tâm cấp cứu A9, Bệnh viện Bạch Mai Chịu trách nhiệm chính: Nguyễn Thị Minh Phương Email: Nguyenminhphuong.yhn@gmail.com Ngày nhận bài: 15.9.2021

Ngày phản biên khoa hoc: 12.11.2021

Ngày duyệt bài: 22.11.2021 12.23 , male $73.8 \%$. The most frequent source is respiratory infection, followed by abdominal and urinary ones, respectively. Overt DIC observed in 34 patients, $55.8 \%$. Compare to D-dimer in diagnosis DIC, AUC of ROC curve, specificity, positive predictive value, negative predictive value of fibrin monomer is higher.

Keywords: septic shock. disseminated intravascular coagulation, DIC, solube fibrinmonomer, D-dimer.

\section{I. ĐăT VẤN ĐỀ}

Sốc nhiễm khuẩn (SNK) là một bệnh lý nặng, xảy ra ở 10-20 \% BN ICU với tỉ lệ tử vong cao $\geq$ $40 \%$ [1]. SNK gây ra hoạt hóa quá trình viêm và hê thống đông cầm máu, dẫn tới các bất thường vi mạch, rối loạn chức năng đa cơ quan, trong đó DIC là một rối loạn thường gặp và nghiêm trong [1]. DIC là hậu quả đồng thời là yếu tố thúc đây,làm nặng thêm tình trạng bênhh,sự phát triển của DIC ở bệnh nhân SNK đã được xác nhận là một yếu tố độc lập tiên lượng tử vong. Kết quả điều trị phụ thuộc vào kiểm soát nhiễm khuẩn, đảm bảo huyết động và điêu chỉnh các rối loạn chức năng bao gồm rối loạn chức năng hệ thống đông máu. Do đó việc chẩn đoán sớm và điêu trị DIC có vai trò quan trọng. Trong bệnh cảnh của sốc nhiễm khuẩn, rối loạn quá trình đông máu do nhiều nguyên nhân như suy các tạng khác như suy gan; giảm tiểu câu do vì khuẩn ức chế tủy xương, do điều trị (heparin, thuốc kháng sinh...), fibrinogen tăng như là một marker viêm; làm giảm độ đặc hiệu của các xét nghiệm đông câm máu. Điều này đặt ra yêu câu cần có một chỉ điểm đủ nhạy, đặc hiệu, tiện lợi trong tính toán, chẩn đoán DIC. Bên cạnh DDimer là xét nghiệm được dùng phổ biển hiện tại, Fibrinmonomer hòa tan(sFM) gân đây cũng được dùng như là một chỉ số cho chẩn đoán DIC với độ nhạy độ đặc hiệu cao, khả năng chẩn đoán sớm [2].

Vì vậy chúng tôi tiến hành nghiên cứu với mục tiêu đánh giá: "Mô tả sơ bộ tình trạng đông máu nội quản và vai trò của xét nghiệm fibrinmonomer hòa tan (SFM) trong chân đoán DIC trên bệnh nhân sốc nhiễm khuẩn". 


\section{II. ĐỐI TƯỢNG VÀ PHƯƠNG PHÁP NGHIÊN CỨU}

\section{1. Đối tượng nghiên cứu}

Đối tượng: Các bệnh nhân được chẩn đoán sốc nhiễm khuẩn theo định nghĩa của sepsis 3.

Địa điểm: Trung tâm cấp cứu $A 9$ bệnh viện Bach Mai

Thời gian: từ tháng 6/2020- tháng 4/2021

Tiêu chuẩn chợn bệnh nhân. Bệnh nhân chẩn đoán Sốc nhiễm khuẩn theo đinh nghĩa của Sepsis-3. Tuổi $\geq 18$ tuổi. Tự nguyện tham gia nghiên cứu

\section{KẾT QUẢ NGHIÊN CỨU}

1.Đặc điểm chung của đối tượng nghiên cứu

1.1 Phân bố theo tuổi của nhóm đối tượng

Bảng 1: Phân bố theo nhóm tuối

\begin{tabular}{|c|c|c|c|}
\hline Nhóm tuối & Số lượng & Tỉ lệ & Phần trăm cộng dồn \\
\hline 27 đến 44 tuối & 7 & $11.5 \%$ & $11.5 \%$ \\
\hline 45 đến 54 tuối & 8 & $13.1 \%$ & $24.6 \%$ \\
\hline 55 đến 64 tuối & 25 & $41 \%$ & $65.6 \%$ \\
\hline$\geq 65$ tuối & 21 & $34 \%$ & $100 \%$ \\
\hline Tống & $\mathbf{6 1}$ & $\mathbf{1 0 0} \%$ & \\
\hline
\end{tabular}

Nhận xét: Tuối trung bình của nhóm đối tượng là $59.95 \pm 12.23$, cao nhất là 85 tuối, thấp nhất là 27 tuổi. Nhóm bệnh nhân $\geq 55$ tuổi chiếm tỉ lệ cao (75\%)

1.2 Phân bố theo giới của nhóm đôi tượng, và tỉ lệ theo giới của nhóm overt DIC và non overt DIC

Bảng 2: Phân bố bệnh nhân chẩn đoán DIC toàn thể theo giới

\begin{tabular}{|c|c|c|c|c|}
\hline & DIC tiềm tàng & DIC toàn thế & Total & P \\
\hline Nữ $\mathrm{N}(\%)$ & $8(13.1 \%)$ & $8(13.1 \%)$ & $17(26.2 \%)$ & \multirow{2}{*}{0.591} \\
\hline Nam $\mathrm{N}(\%)$ & $19(31.1 \%)$ & $26(42.7 \%)$ & $44(73.8 \%)$ & \\
\hline Tống $\mathrm{N}(\%)$ & $27(44.2 \%)$ & $34(55.8 \%)$ & $61(100 \%)$ & \\
\hline
\end{tabular}

Nhận xét: Số bênh nhân nam nhiều hơn số bênh nhân nữ. Trong đó, tỉ lệ bênh nhân nữ chiếm $26.2 \%$, bệnh nhân nam chiếm $73.8 \%$. Số bệnh nhân DIC toàn thể là 34 bệnh nhân chiếm $55.8 \%$, DIC tiềm tàng là 27 bệnh nhân chiếm $44.2 \%$.

Không có sự khác biệt về tỉ lệ DIC toàn thể theo giới với $p=0.591$

\section{3 Đường vào của nhiếm trùng}

Bảng 3: Phân bố theo đường vào của ổ nhiễm trùng

\begin{tabular}{|c|c|c|c|c|}
\hline Đường vào & DIC toàn thế & DIC tiềm tàng & Tống & $\mathbf{p}$ \\
\hline Hô hấp N(\%) & $12(19.7 \%)$ & $12(19.7 \%)$ & $24(39.3 \%)$ & \multirow{6}{*}{0.479} \\
\hline Tiết niệu N(\%) & $7(11.5 \%)$ & $7(11.5 \%)$ & $14(23 \%)$ & \\
\hline Ö bụng N(\%) & $9(14.8 \%)$ & $7(11.5 \%)$ & $16(26.2 \%)$ & \\
\hline Mô mềm/Cơ xương khớp N(\%) & $3(4.9 \%)$ & $1(1.6 \%)$ & $4(6.6 \%)$ & \\
\hline Đường mât N(\%) & $3(4.9 \%)$ & $0(0 \%)$ & $3(4.9 \%)$ & \\
\hline Tống N(\%) & $34(55.7 \%)$ & $27(44.3 \%)$ & $61(100 \%)$ & \\
\hline
\end{tabular}

Nhận xét: Số bệnh nhân có đường vào từ hô hấp chiếm tỉ lệ cao nhất với 24 bệnh nhân( $39.3 \%)$.

Đường vào từ ổ bụng đứng thứ 2 với 16 bệnh nhân, chiếm $26.2 \%$

Sự khác biệt về tỉ lệ bệnh nhân DIC toàn thể giữa các nhóm nguyên nhân không có ý nghĩa thống kê với $p=0.497$

\subsection{Kêt cục của nhóm đôi tương trong nghiên cứu}

Bảng 4. Kết cục điều trị bệnh nhân

\begin{tabular}{|c|c|c|c|c|}
\hline & Tử vong hoặc xin về & Thoát sốc & Tống & \multirow{2}{*}{ P } \\
\hline DIC tiềm tàng $\mathrm{n}(\%)$ & $13(48.1 \%)$ & $14(51.9 \%)$ & $27(100 \%)$ & \multirow{2}{*}{0.022} \\
\hline DIC toàn thể $\mathrm{n}(\%)$ & $26(76.5 \%)$ & $8(23.5 \%)$ & $34(100 \%)$ & \\
\hline Tống & $\mathbf{4 1 ( 6 3 . 9 \% )}$ & $\mathbf{2 0}(\mathbf{3 6 . 1 \%} \%)$ & $\mathbf{6 1 ( 1 0 0 \% )}$ & \\
\hline
\end{tabular}


Nhận xét: tổng số bệnh nhân thoát sốc là 22 chiếm $36.1 \%$, số bệnh nhân tử vong hoặc xin về là 41 bệnh nhân chiếm $63.9 \%$. Trong đó, số bệnh nhân tử vong hoặc xin về của nhóm DIC toàn thể có tỉ lệ cao hơn nhóm DIC tiềm tàng, sự khác biệt có ý nghĩa thông kề với $p=0.022$

2. Vai trò của sFM trong chấn đoán DIC

Bảng 6. So sánh giá trị chẩn đoán của SFM và DDimer trong chẩn đoán DIC

\begin{tabular}{|c|c|c|c|c|c|}
\hline & Điểm cắt & Độ nhạy & Độ đặc hiệu & $\begin{array}{c}\text { Giá trị dự báo } \\
\text { dương tính }\end{array}$ & $\begin{array}{c}\text { Giá trị dự } \\
\text { báo âm tính }\end{array}$ \\
\hline Sfm $(\mathrm{mg} / \mathrm{l})$ & 15.25 & $67.6 \%$ & $70.4 \%$ & $74.19 \%$ & $63.33 \%$ \\
\hline DDimer $(\mathrm{mg} / \mathrm{l})$ & 6.635 & $70.6 \%$ & $51.9 \%$ & $64.86 \%$ & $58.33 \%$ \\
\hline
\end{tabular}

Bảng 7. So sánh giá trị chấn đoán DIC của sFM và D-Dimer

\begin{tabular}{|c|c|c|c|c|}
\hline & Điếm cắt & OR & $\mathbf{9 5 \% C I}$ & $\mathbf{p}$ \\
\hline SFM & 15.25 & 4.97 & $1.66-14.84$ & 0.03 \\
\hline D-Dimer & 6.63 & 2.58 & $0.899-7.427$ & 0.075 \\
\hline
\end{tabular}

Nhận xét: Tại điểm cắt của sFM bằng $15.25(\mathrm{mg} / \mathrm{l})$, điểm cắt của $\mathrm{D}$-dimer $6.635(\mathrm{mg} / \mathrm{l})$,sFM có khả năng chẩn đoán tốt hơn D-dimer.

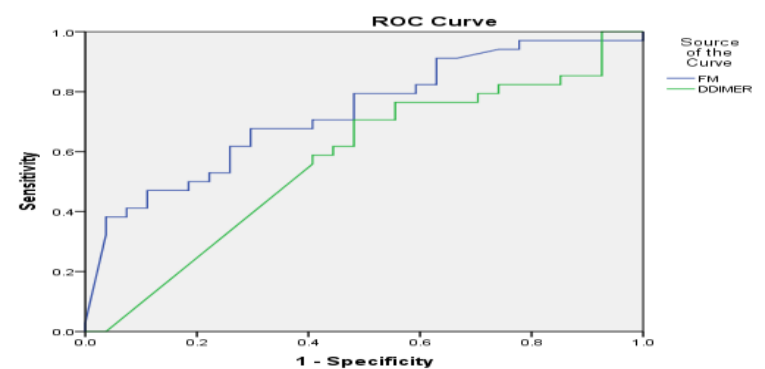

Biểu đồ 1: đường cong ROC của SFM và DDimer trong chẩn đoán DIC

Nhận xét: Diện tích dưới đường cong của sFM trong chẩn đoán DIC bằng 0.731 có giá trị trung bình trong chẩn đoán DIC, có ý nghĩa thông kê với độ tin cậy 95\%, CI 95\%(0.606-0.856).

Diện tích dưới đường cong của Ddimer bằng 0.572 có giá trị thấp trong chẩn đoán DIC, $\mathrm{p}=$ 0.338, CI 95\%(0.424-0.719).

\section{BÀN LUÂ̂N}

1. Phân bố theo tuổi của nhóm đối tượng nghiên cứu. Bệnh nhân có độ tuổi trung bình $59.95 \pm 12.23$, tương tự trong nghiên cứu của Nguyễn Thanh Thủy với tuổi trung bình 61,4 $\pm 15,2$ [3], trong đó nhóm bệnh nhân cao tuổi ( $\geq 55$ tuối) chiếm tỉ lệ cao với $75 \%$.

2.Tỉ lệ bệnh nhân đông máu nội quản rải rác và phân bố theo giới. Trong nghiên cứu của chúng tôi, tỉ lệ bệnh nhân đông máu nội quản rải rác là $34 / 61$ bểnh nhân chiếm $55.8 \%$ tương tự trong nghiên cứu của Gando với 50.7\%[4]

Trong nhóm đối tượng tỉ lệ bênh nhân nam là 44 bệnh nhân chiếm $72.1 \%$, không có sự khác biệt vềtỉ lệ mắc DIC công khai theo giới. Kết quả nghiên cứu tương tượng trong nghiên cứu của Nguyễn Thanh Thủy [3]

3. Phân bố theo đường vào của nhóm đối tượng nghiên cứu. Số bệnh nhân có đường vào từ hô hấp chiếm tỉ lệ cao nhất với 24 bệnh nhân (39.3\%). Đường vào từ ổ bụng đứng thứ 2 với 16 bệnh nhân, chiếm $26.2 \%$, đường vào từ tiết niệu đứng thứ 3 với 14 bệnh nhân chiếm $23 \%$. Đường vào mô mềm và cơ xương khớp đứng thứ 4 với 4 bệnh nhân chiếm $6.6 \%$. Đường mật đứng thứ 5 với 3 bệnh nhân, chiếm $4.9 \%$. Khổng có bệnh nhân nào có đường vào tù̀ thần kinh. Phân bố tương tự trong nghiên cứu của Nguyễn Hữu Quân [5]. Sự khác biệt về tỉ lệ bệnh nhân overt DIC giữa các nhóm nguyên nhân không có ý nghĩa thống kê với $p=0.497$

4. Kết cục điều trị. Số bệnh nhân thoát sốc là 22 bệnh nhân chiếm $36.1 \%$, số bệnh nhân có kết cục xấu (tử vong hoặc xin về) là 41 bệnh nhân chiếm $63.9 \%$. Tỉ lệ tử vong tương tự nghiên cứu của Nguyễn Xuẩn Nam với 66\% [6]

Tỉ lệ bệnh nhân có kết cục xấu trong nhóm overt DIC chiếm $76.5 \%$ cao hơn trong nhóm non-overt DIC (48.1\%), sự khác biệt có ý nghĩa thống kê với $p=0.022$

5. Vai trò của sFM trong chẩn đoán đông máu nội quản rải rác. Trong nghiên cứu của chúng tồi, trên đối tượng bệnh nhân sốc nhiễm khuẩn, để phân biệt bệnh nhân DIC công khai và bệnh nhân DIC tiềm tàng, sFM có giá trị cao hơn với giá trị dưới đường cong ROC của SFM bằng 0.731 , và của Ddimer 0.572 . Sử dụng $s F M$ để chẩn đoán DIC toàn bộ có độ nhạy tương tự DDimer (67.6\% so với 70.6\%), nhưng độ đặc hiệu cao hơn (70.4\% so với $51.9 \%)$. Tại điểm cắt được xác định, sFM cho giá trị dự báo dương tính và giá trị dự đoán âm tính cao hơn DDimer. Kết quả này khá tương đồng với các nghiên cứu khác trên thế giới của [2], [7], [8]. Nồng độ sFM $\geq 15.25$ có khả năng dự đoán DIC toàn thể với OR 4.97, 95CI (1.66-14.84), có ý nghĩa thống kê với $\mathrm{p}=0.03$.

\section{KẾT LUẬN VÀ KIẾN NGH!}


Bệnh nhân sốc nhiễm khuẩn là nhóm đối tượng nặng, tỉ lệ tử vong cao trong ICU. Sự xuất hiện đông máu nội quản rải rác dự báo kết cục xấu hơn trên nhóm bệnh nhân này. SFM có giá trị trong chẩn đoán DIC, làm tăng độ đặc hiệu, giá trị dự báo âm tính, giá trị dự báo dương tính so với D-Dimer tuy nhiên độ nhạy thấp hơn.

\section{TÀI LIẸU THAM KHẢO}

1. Opal S.M., Laterre P.-F., Francois B. và công sự. (2013). Effect of eritoran, an antagonist of MD2-TLR4, on mortality in patients with severe sepsis: the ACCESS randomized trial. Jama, 309(11), 1154-1162.

2. Park K.-J., Kwon E.-H., Kim H.-J. và cộng sự. (2011). Evaluation of the diagnostic performance of fibrin monomer in disseminated intravascular coagulation. Korean J Lab Med, 31(3), 143-147.

3. Nguyê̂n T.T. (2021). IDJặc Idjiểm lâm sàng, cận lâm sàng và một số yếu tố liên quan Idjên kết quả
Idjiều trị bệnh nhân sốc nhiễm khuẩn tại Bệnh viện Trung ương Thái Nguyên/Nguyễn Thanh Thủy. .

4. Gando S., Shiraishi A., Yamakawa K. và cộng sứ. (2019). Role of disseminated intravascular coagulation in severe sepsis. Thromb Res, 178, 182-188.

5. Quân N.H. nghiên cứu hiệu quả huyết động với sự hổ trợ của phqớng pháp picco trong xử trí sốc nhiếm khuẩn. 174.

6. Nguyễn Xuân N. (2009). Đánh giá hiệu quả của lọc máu liên tục trong điều trị suy đa tạng do sốc nhiếm khuẩn. .

7. Singh N., Pati H.P., Tyagi S. và cộng sự. (2017). Evaluation of the diagnostic performance of fibrin monomer in comparison to d-dimer in patients with overt and nonovert disseminated intravascular coagulation. Clin Appl Thromb, 23(5), 460-465.

8. Refaai M.A., Riley P., Mardovina T. và cộng sự. (2018). The clinical significance of fibrin monomers. Thromb Haemost, 118(11), 1856-1866.

\section{ĐÁNH GIÁ HIỆU QUẢ CỦA PHÁC Đồ Có RITUXIMAB TRONG ĐIỀU TRI BƯớC ĐẦU U LYMPHO THỂ NANG TẠI BỆNH VIỆN K}

\section{Nguyễn Tiến Quang ${ }^{1}$, Đỗ Huyền Nga ${ }^{1}$, Nguyễn Thanh Tùng ${ }^{1}$}

\section{TÓM TẮT}

Mục tiêu: Đánh giá hiệu quả của phác đồ có Rituximab trong điều trị bước đâu u lympho thể nang tại bệnh viện $K$. Đối tượng và phương pháp: Nghiên cứu mô tả tiến cứu trên 24 bệnh nhân u lympho thể nang điều trị bước đầu bằng phác đồ có rituximab từ tháng $5 / 2019$ đến tháng $10 / 2021$. Kết quả: Độ tuổi trung bình của bệnh nhân là 59,71 , tỉ lệ giới tính trong nghiên cứu là nam/nữ $=2$, đa số bệnh nhân vào viện vì nổi hạch 70,7\%; đa số bệnh nhân ở giai đoan 3 chiếm $62 \%$; nhóm điêuu trị bằng phác đồ RB có tỉ lệ đáp ứng toàn bộ $100 \%$. nhóm điều trị bằng $\mathrm{RCHOP} / \mathrm{RCVP}$ có tỉ lê đáp ứng toàn bộ là $87,4 \%$. Tỉ lế bệnh nhân gặp độc tính khi điều trị phác đổ RCंHOP/RCVP 75\% trong khi nhóm điêu trị RB chỉ găp độc tính 25\%. Kết luận: Phác đồ RB cho tỉ lệ đáp ứng và tính an toàn cào hơn phác đồ RCHOP/RCVP trong điều trị bước đầu u lympho thể nang.

Tư khóa: u lympho thể nang

\section{SUMMARY \\ ASSESSMENT THE EFFECTIVENESS OF RITUXIMAB REGIMENS IN THE FIRST LINE TREATMENT OF FOLLICULAR LYMPHOMA AT K HOSPITAL}

\footnotetext{
*Bệnh viện $K$

Chịu trách nhiệm chính: Nguyễn Tiến Quang

Email: ntienquangbvk@gmail.com

Ngày nhận bài: 14.9.2021

Ngày phản biện khoa học: 10.11.2021

Ngày duyệt bài: 17.11.2021
}

Objectives: To evaluate the effectiveness of a rituximab regimens in the first line treatment of follicular lymphoma at K hospital. Subjects and methods: A prospective descriptive study conducted on 24 follicular lymphoma patients treated with rituximab regimens from May 2019 to October 2021. Results: The average age of the patients was 59.71 , the sex ratio male/female was 2.0 , almost patients were hospitalized because of lymphadenopathy $70.7 \%$; almost patient have stage 3 accounted for $62 \%$; The overall response rate of RB group was $100 \%$. The overall response rate of RCHOP/RCVP group was $87.4 \%$. The toxicity rate of RCHOP/RCVP group was $75 \%$ while the toxicity rate of the RB group was $25 \%$. Conclusion: The RB regimen has a higher response rate and safety than the RCHOP/RCVP regimen in the first line treatment of follicular lymphoma.

Key words: follicular lymphoma (FL)

\section{I. ĐẶT VẤN ĐỀ}

U lympho dạng nang (FL-Follicular Lymphoma) là loại u lympho không Hodgkin (NHL-non Hodgkin lymphoma) phổ biến thứ hai chiếm khoảng 20\%-35\%. Đây là bệnh phổ biến nhất trong số các NHL tiến triển chậm trên lâm sàng ${ }^{1}$.

Ở Hoa Kỳ, FL chiếm khoảng $35 \%$ các NHL và có tỷ lệ mắc ước tính là 3,18 trường hợp trên 100.000 người. Tỷ lệ mắc bệnh ổn định theo thời gian, nhưng thay đổi theo chủng tộc, với tỷ lệ mắc bệnh ở người da trắng cao hớn hai lân so với dân số châu Phi và châu Á. Tỉ lệ mắc bệnh tương đương ở hai giới. Tỉ lệ mắc bệnh tăng dân 